\title{
Selective Effects of Hyperprolactinemia on in vitro Dopamine Release from Median Eminence Synaptosomes
}

\author{
K. A. Gregerson and Michael Selmanoff \\ Department of Physiology, University of Maryland, School of Medicine, Baltimore, Maryland 21201
}

Prolactin is thought to exert an autoregulatory, negative feedback effect on its own secretion via stimulation of the tuberoinfundibular dopaminergic (TIDA) neurons. To investigate possible mechanisms involved in this feedback, the effects of experimentally induced hyperprolactinemia on the release of ${ }^{3} \mathrm{H}$-dopamine ( ${ }^{3} \mathrm{H}$-DA) were studied in nerve terminals (synaptosomes) isolated from rat median eminence (ME), the TIDA neuronal projection field. Synaptosomes were prepared from adult male rats treated with ovine prolactin (OPRL) or the vehicle for $48 \mathrm{hr}$. Synaptosomes were incubated in $0.1 \mu \mathrm{M}{ }^{3} \mathrm{H}-\mathrm{DA}$ at $30^{\circ} \mathrm{C}$ until steady-state conditions were achieved, and then release of the preaccumulated transmitter was measured over 1-20 sec time intervals under basal and depolarizing conditions.

Release of ${ }^{3} \mathrm{H}-\mathrm{DA}$ ellcited by depolarization of the terminals was significantly greater in ME synaptosomes prepared from oPRL-treated animals as compared with preparations from controls. This effect of the hyperprolactinemia appeared to be specific to the TIDA neurons since OPRL treatment did not result in increased evoked release of ${ }^{3} \mathrm{H}-\mathrm{DA}$ from terminals prepared from the mesolimbic, tuberohypophyseal, or nigrostriatal dopaminergic neurons. Basal efflux in all preparations was not changed from controls.

The increased evoked release in oPRL-treated ME occurred when depolarization was induced either with high external $[\mathrm{KCl}]$ or veratridine. The enhanced ${ }^{3} \mathrm{H}-\mathrm{DA}$ efflux was evident during depolarization over a wide range of external calcium concentrations $(0.01-3.0 \mathrm{~mm})$, in the presence of 20 $\mathrm{mM} \mathrm{Ni}^{2+}$ to block $\mathrm{Ca}^{2+}$ influx through voltage-gated channels, or when all external $\mathrm{Ca}^{2+}$ had been chelated, indicating that this effect of oPRL involves DA released through a mechanism independent of external calcium.

Dopamine (DA) released from terminals of the tuberoinfundibular dopaminergic (TIDA) neurons in the median eminence (ME) acts as a physiological prolactin (PRL)-inhibiting hormone responsible for tonic regulation of basal prolactin secretion (for reviews, see Weiner et al., 1979; Leong et al., 1983). Evidence for an autoregulatory action of PRL on its own secretion was first reported by Clemens and Mcitcs (1968). It was latcr demonstrated that DA turnover in the ME of rats was elevated by

Received July 8, 1987; revised Oct. 26, 1987; accepted Nov. 3, 1987.

This work was supportcd by NIH Grants IID-06481 to K.A.G. and NS-14611, NS-0073I, and HD-21351 to M.S.

Correspondence should be addressed to Dr. K. A. Gregerson, Department of Pediatrics, Room 10-039 FCBRL, University of Maryland, School of Medicine, 655 West Baltimore Street, Baltimore, MD 21201

Copyright (C) 1988 Society for Neuroscience $0270-6474 / 88 / 072477-08 \$ 02.00 / 0$
PRL treatment (Hökfelt and Fuxe, 1972), suggesting that the PRL feedback is mediated, at least in part, by tuberoinfundibular DA. Stimulation of TIDA neuronal activity by PRL has been supported by many subsequent studies using a variety of methods to introduce the PRL: cerebroventricular injection (Annunziato and Moore, 1978); ectopic pituitary grafts (Olson et al., 1972; Höhn and Wuttke, 1978); PRL-secreting pituitary tumor implants (Perkins et al., 1979); and systemic injection (Gudelsky et al., 1976; Selmanoff, 1981, 1985). Administration of PRL also significantly elevates DA in the hypophyseal portal blood (Cramer et al., 1979; Gudelsky and Porter, 1980). These observations are consistent with an increase in DA release from the nerve terminals in the ME, and, indeed, PRL has been shown to augment DA release from medial basal hypothalamic fragments superfused in vitro (Perkins and Westfall, 1978; Foreman and Porter, 1981). However, the mechanism by which PRL effects these changes is unknown.

In this report, we present our observations of PRL-induced alterations in DA uptake and release in nerve terminals isolated from the median eminence of rats. We used synaptosomes preloaded with labeled DA in order to focus on possible PRL-induced alterations in the release characteristics of the neurotransmitter and minimize confounding manifestations of potential changes in its synthesis. In all experiments, synaptosome preparations from the corpus striatum, a dopaminergic system not believed to be involved in PRI, regulation, were examined concurrently with the ME terminals for comparison.

\section{Materials and Methods}

Animals. Male Sprague-Dawley rats (200-250 gm) were purchased from Zivic-Miller Laboratories, Inc. (Allison Park, PA). Animals were maintained on a 14:10 light : dark schedule (lights on at 0400) with food and water available ad libitum. Hyperprolactinemia was experimentally induced by injecting ovine prolactin (oPRL) provided through the NIADDK National Hormone and Pituitary Program (NIADDK-oPRL16; biopotency, $30.5 \mathrm{IU} / \mathrm{mg}$ ). The use of the heterologous PRL preparation allowed both the endogenous rat prolactin (rPRL) and the OPRL to be monitored in the same rats. Using this experimental model, we have previously demonstrated PRL feedback as evidenced by increased turnover of DA in TIDA neurons (Selmanoff, 1981, 1985) and suppression of basal secretion of endogenous PRL (Selmanoff and Gregerson, 1984; Selmanoff, 1985). The oPRL was dissolved in $0.01 \mathrm{M} \mathrm{NaHCO}_{3}$ $\left(\mathrm{pH} 8.6,25^{\circ} \mathrm{C}\right.$ ) and administered subcutaneously at a dose of $4 \mathrm{mg} / \mathrm{kg}$, every $8 \mathrm{hr}$ for a total of $48 \mathrm{hr}$. Subcutaneous injections at this dose produce a serum oPRL profile with peak values of $\sim 2000 \mathrm{ng} / \mathrm{ml} \mathrm{oc-}$ curring approximately $2 \mathrm{hr}$ postinjection followed by a decline to $\sim 10$ $\mathrm{ng} / \mathrm{ml}$ by $8 \mathrm{hr}$ postinjection (Selmanoff and Gregerson, 1984; Selmanoff, 1985). Solutions of oPRL were prepared fresh for each experiment and were not used beyond $48 \mathrm{hr}$ following its reconstitution in the $\mathrm{NaHCO}_{3}$ buffer. Control animals received injections of the vehicle.

Animals were decapitated between 1 and $2 \mathrm{hr}$ following the last injection. MEs ( $\sim 0.4 \mathrm{mg}$ wet weight each) and, for all experiments, com- 
parably sized fragments from the caudate nucleus of the corpus striatum (CS) were rapidly dissected and immediately transferred to homogenization tubes containing ice-cold $0.32 \mathrm{M}$ sucrose with $2.5 \mathrm{M}$ HEPES$\mathrm{HCl}\left(\mathrm{pH} 7.4,4^{\circ} \mathrm{C}\right)$ and $0.1 \% \mathrm{BSA}$. In a few experiments, the posterior pituitary gland (neural and intermediate lobes) and fragments of the olfactory tubercle and nucleus accumbens were also dissected. Twelve to 20 animals per group were used for each experiment, and tissues were pooled according to group for the preparation of synaptosomes. Serum was harvested from the trunk blood of individual animals and stored at $-20^{\circ} \mathrm{C}$ until assayed for oPRL and endogenous rPRL. In one series of studies, animals were bilaterally orchidectomized under ether anesthesia $10 \mathrm{~d}$ prior to the onset of hormone treatment.

Synaptosome preparation. Tissues were homogenized in glass-Teflon tissue grinders $(0.10-0.15 \mathrm{~mm}$ clearance) and synaptosomes prepared through a series of homogenizations and centrifugations according to a modification (Krueger et al., 1979) of the method of Hajos (1975). The crude $\mathrm{P}_{2}$ fraction was used without further purification on a gradient. Synaptosomes, suspended in $0.32 \mathrm{M}$ sucrose, were equilibrated into a physiological saline solution by gradual addition, over a $30 \mathrm{~min}$ period, of $2.5 \mathrm{vol}$ of ice-cold " $5 \mathrm{~K}$ " solution containing $5 \mathrm{~mm} \mathrm{KCl,} 75 \mathrm{~mm} \mathrm{NaCl}$, $70 \mathrm{~mm} N$-methyl-D-glucamine, $1 \mathrm{~mm} \mathrm{MgCl}, 10 \mathrm{~mm}$ glucose, $10 \mathrm{~mm}$ HEPES- $\mathrm{HCl}\left(\mathrm{pH} 7.4,25^{\circ} \mathrm{C}\right.$ ), and $0.1 \%$ BSA. Synaptosomes were centrifuged a final time and resuspended in the $5 \mathrm{~K}$ solution at a concentration of 200-300 $\mu$ g protein $/ \mathrm{ml}$.

Synaptosomes were allowed to incorporate ${ }^{3} \mathrm{H}-\mathrm{DA}$ by incubation for $30 \mathrm{~min}$ at $30^{\circ} \mathrm{C}$ in $0.1 \mu \mathrm{M}{ }^{3} \mathrm{H}-\mathrm{DA}$ (New England Nuclear Corporation, Boston; specific activity, $41.5 \mathrm{Ci} / \mathrm{mmol}$ ), $0.5 \mathrm{~mm}$ ascorbic acid (to prevent oxidation of the DA), $0.05 \mathrm{~mm}$ pargyline (an MAO inhibitor), and $0.5 \mathrm{~mm}$ desipramine (to prevent nonspecific uptake of ${ }^{3} \mathrm{H}$-DA into noradrenergic terminals; see Koe, 1976). Under these conditions, uptake of the ${ }^{3} \mathrm{H}-\mathrm{DA}$ reached steady state within $30 \mathrm{~min}$ and remained stable for at least an additional $90 \mathrm{~min}$. Release experiments were completed well within this time frame.

${ }^{3} \mathrm{H}-\mathrm{DA}$ release experiments. Release of the preaccumulated ${ }^{3} \mathrm{H}-\mathrm{DA}$ from the synaptosomes was measured as previously described (Gregerson and Selmanoff, 1987). Briefly, an aliquot of preloaded synaptosome suspension (50 $\mu \mathrm{l}$ vol, $10-15 \mu \mathrm{g}$ protein) was pipetted onto a glass fiber filter (grade \#25, Schleicher and Scheull, Inc., Keene, NH) secured within a well of a filtration manifold. Solutions introduced into the wells of the manifold flow continuously over the synaptosomes trapped on the filters, due to gravitational force alone $(\sim 4.8 \mathrm{ml} / \mathrm{min}$ flow rate). In addition, application of a gentle vacuum draws remaining fluid through very rapidly $(>1 \mathrm{ml} / \mathrm{sec}$ ). The effluent is collected in vials positioned beneath each well. After removal of the loading medium by vacuum filtration, the synaptosomes were washed with $5 \mathrm{~K}$ solution $\left(30^{\circ} \mathrm{C}\right)$ to remove unincorporated ${ }^{3} \mathrm{H}$-DA. Washes were discarded, and the release of incorporated ${ }^{3} \mathrm{H}$-DA from the isolated terminals was initiated by addition of an aliquot of test solution $\left(30^{\circ} \mathrm{C}\right)$ to the well. Efflux was rapidly quenched at various times $(1-20 \mathrm{sec})$ by the addition of a "stop" solution (Drapeau and Blaustein, 1983; Gregerson and Selmanoff, 1987), which was an ice-cold $5 \mathrm{~K}$ solution containing $20 \mathrm{mM} \mathrm{NiCl}_{2}$, a calcium channel blocker. This was immediately followed by application of the vacuum to draw any remaining solution through the filter into the vial below.

Basal efflux of ${ }^{3} \mathrm{H}$-DA was measured in response to a pulse of $5 \mathrm{~K}$ solution. Evoked release was measured in response to a pulse of a depolarizing solution often containing calcium. Depolarization was elicited either by adjusting the external $\mathrm{KCl}$ concentration to $75 \mathrm{~mm}$ by iso-osmotic substitution of $N$-methyl-D-glucamine or by addition of 100 $\mu \mathrm{M}$ veratridine (Aldrich Chemicals, Milwaukee, WI) to the control $5 \mathrm{~K}$ solution. External $\mathrm{NaCl}$ concentration was held constant to avoid possible effects on the $\mathrm{Na}^{+}$-dependent DA carrier (Bruinvels, 1975; Raiteri and Levi, 1978).

Both the uptake and subsequent release of ${ }^{3} \mathrm{H}-\mathrm{DA}$ were calculated from the tritium in the collected effluent and that trapped on the filters as quantitated by liquid scintillation spectroscopy. Following subtraction of background radioactivity in the effluent and filters (determined under assay conditions in the absence of synaptosomes), total ${ }^{3}$ II-DA uptake into the synaptosomes was determined to be the sum of the dpm in the effluent and those trapped on the filters. Release is presented as the percentage of the total incorporated $\mathrm{cpm}$ subsequently measured in the effluent. This expression of "fractional release" normalizes for intersample and interexperimental variation in ${ }^{3} \mathrm{H}-\mathrm{DA}$ uptake and may be indicative of the size of the "releasable pools" of neurotransmitter in a given preparation. Representative aliquots of each preparation were assayed for protein content by the dye-binding microassay of Bradford (1976).

Since the size of the dissected tissues precluded preparations from individual animals and required isolating the terminals from pooled tissues, it was necessary to repeat all experiments on multiple, independent synaptosome preparations. The data presented illustrate the means of values determined in 2-6 independent experiments (i.e., different synaptosome preparations). The value obtained for each parameter within one experiment was determined by $4-6$ replicate measurements. Bars indicating the SEM are drawn unless they fall within the symbols.

Assay of serum prolactin. Rat and ovine PRL were determined on individual serum samples by homologous double-antibody radioimmunoassays (Niswender et al., 1969) using reagents provided by the NIADDK through the National Hormone and Pituitary Program. Endogenous serum rPRL was assayed using rPRL-I-5 and anti-rPRL-S-9. The sensitivity of the assay was $50 \mathrm{pg}$ rPRL-RP-3 (biopotency, $30 \mathrm{IU} /$ $\mathrm{mg}$, which is 2.8 times more potent than RP-1 and equipotent to RP2). Circulating oPRL was assayed using oPRL-I-1 and anti-oPRL-1. The sensitivity of the assay was $100 \mathrm{pg}$ oPRL-I-1 (biopotency, 35 IU/ $\mathrm{mg}$ ).

Statistics. Statistical analysis of radioimmunoassay data and uptake data was performed by Student's $t$ test. Nonparametric statistical tests were employed for analysis of the release data since these were percentages of another variable (uptake) and, thus, are considered to comprise a population in which the criterion scores are not normally distributed. The Mann-Whitney $U$ test was used to compare pairs of means (oPRL versus control) in Figures $1 B, 3$, and 6. A univariate repeatedmeasures analysis of variance (Winer, 1971) was implemented ("PROC GLM" of SAS Institute Inc., 1985) to assess the effect of oPRL treatment on the time course and calcium dose response of ${ }^{3} \mathrm{H}-\mathrm{DA}$ efflux. To use this type of analysis, it was first established that certain assumptions regarding the structure of the covariance matrices were satisfied so that the $F$-ratios of the "within subject" factors (i.e., time and calcium dose) followed an exact $F$ distribution (Huynh and Feldt, 1970; Rouanet and Lepine, 1970). In other words, it was determined that the covariance of the preparations was not different between experiments.

\section{Results}

Steady-state uptake of ${ }^{3} \mathrm{H}-\mathrm{DA}$ was suppressed in ME synaptosomes prepared from oPRL-treated animals compared with preparations from control animals (Fig. $1 A$ ). In contrast, ${ }^{3} \mathrm{H}-$ DA incorporation into CS synaptosomes was enhanced following in vivo exposure to oPRL. From preparation to preparation, the suppression of uptake in ME terminals ranged from 12 to $21 \%$, while the increased steady-state accumulation into CS synaptosomes from oPRL-treated animals ranged from 18 to $25 \%$. These divergent effects of hyperprolactinemia on steady-state ${ }^{3} \mathrm{H}$-DA uptake into terminals isolated from these 2 brain regions was a consistent finding in all the studies presented.

Figure $1 B$ illustrates the subsequent release of the ${ }^{3} \mathrm{H}-\mathrm{DA}$ from the same preparations presented in Figure 1.4. Increasing the external $\mathrm{KCl}$ concentration from 5 to $75 \mathrm{~mm}$, thereby depolarizing the synaptosomes (Blaustein and Goldring, 1975), evoked a substantial increase in the efflux of the neurotransmitter from both ME and CS synaptosomes. Despite the oPRL-induced decrease in $\mathrm{ME}$ accumulation of the labeled DA, this preparation displayed a selective increase in the evoked release of preloaded ${ }^{3} \mathrm{H}-\mathrm{DA}$. The rclcasc data is presented as fractional release and, thus, adjusts for the lower quantity of ${ }^{3} \mathrm{H}$-DA accumulated in the oPRL-treated group. However, in most preparations, the augmentation in depolarization-induced release from $\mathrm{ME}$ synaptosomes following hyperprolactinemia was such that the increase was detectable in the absolute values of release, prior to being normalized for the differences in uptake. Basal efflux in the ME preparation was unchanged from controls (Fig. 1B). The hormone treatment did not alter the fractional ${ }^{3} \mathrm{H}-\mathrm{DA}$ release 


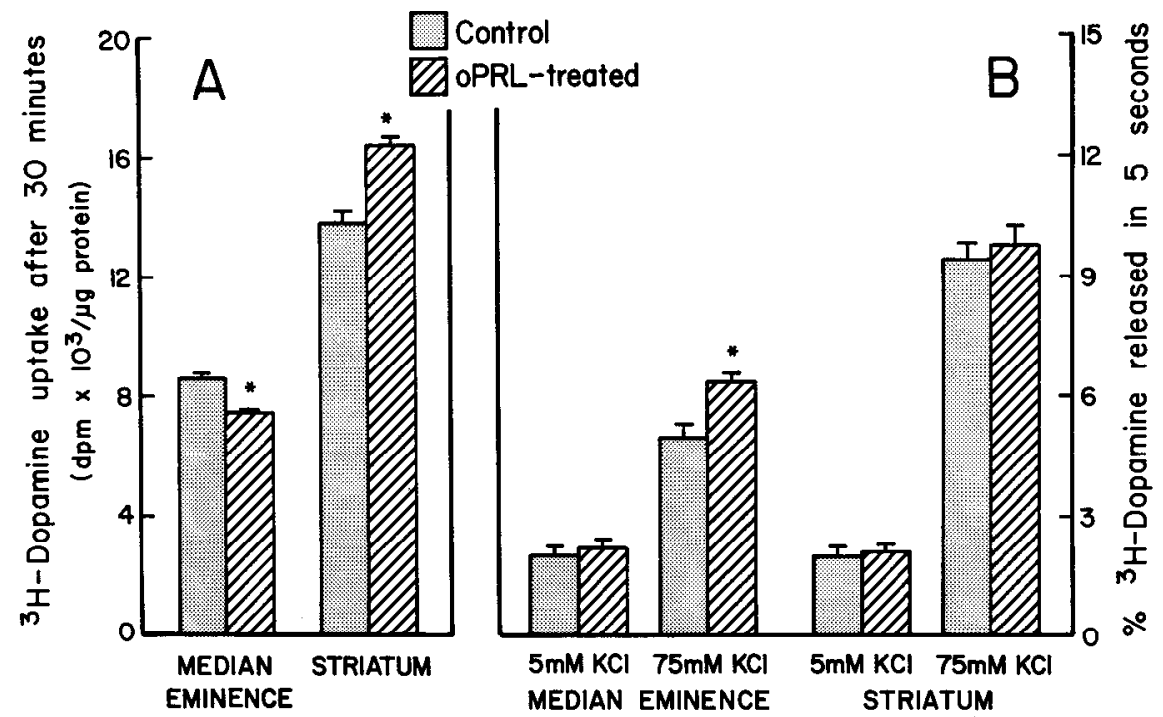

Figure 1. Effect of in vivo oPRL administration on the steady-state uptake $(A)$ and subsequent release $(B)$ of ${ }^{3} \mathrm{H}-\mathrm{DA}$ in synaptosomes prepared from $M E$ and CS. Rats were treated with oPRL or vehicle for $48 \mathrm{hr}$ prior to decapitation. Synaptosomes prepared from $M E$ and $C S$ were incubated in 0.1 $\mu \mathrm{M}{ }^{3} \mathrm{H}-\mathrm{DA}$ for at least $30 \mathrm{~min}$ at $30^{\circ} \mathrm{C}$. Uptake was terminated when aliquots $(50 \mu 1)$ of loaded synaptosome suspensions were filtered and washed. Release of the incorporated ${ }^{3} \mathrm{H}-\mathrm{DA}$ was measured during a $5 \mathrm{sec}$ incubation with 5 or $75 \mathrm{~mm} \mathrm{KCl}$ solution. Data are expressed as means \pm SEM of values obtained in 6 independent experiments. *Different at $p<0.001$ from corresponding control group.

from CS synaptosomes under either basal or depolarizing conditions (Fig. $1 B$ ).

In addition to the differential responses to the oPRL treatment, it can be seen in the control data in Figure $1, A, B$, that there existed quantitative differences between ME and CS synaptosome preparations with regard to both ${ }^{3} \mathrm{H}-\mathrm{DA}$ uptake and release. Under steady-state conditions, ${ }^{3} \mathrm{H}-\mathrm{DA}$ accumulation into CS synaptosomes was 1.5 - to 2-fold greater than that into terminals prepared from the ME (Fig. 1 $A$ ). Also, the quantity of the accumulated ${ }^{3} \mathrm{H}-\mathrm{DA}$ released during a $5 \mathrm{sec}$ depolarization was much greater from the CS preparation. This was true even when the data were normalized for the differences in the incorporation of the labeled neurotransmitter (Fig. $1 B$ ). These quantitative differences in incorporation and evoked fractional re- lease of ${ }^{3} \mathrm{H}-\mathrm{DA}$ between $\mathrm{ME}$ and $\mathrm{CS}$ have been observed throughout our studies (Gregerson and Selmanoff, 1987; present report).

Figure $2 A-D$ illustrates the time courses of ${ }^{3} \mathrm{H}$-DA efflux from ME and CS synaptosomes prepared from both oPRL- and vehicle-treated rats. Again, the data show an enhanced fractional release of ${ }^{3} \mathrm{H}$-DA from ME synaptosomes of hyperprolactinemic rats during depolarization, while the basal efflux of the preloaded neurotransmitter did not differ in oPRL-treated and control groups. Analysis of the profiles revealed that the enhanced release in ME during stimulation with $75 \mathrm{~mm} \mathrm{KCl}$ was significant at $1 \mathrm{sec}$ and thereafter increased as depolarization was maintained (Fig. 2A). Augmented ${ }^{3} \mathrm{H}-\mathrm{DA}$ release from ME synaptosomes of hyperprolactinemic rats was also observed when

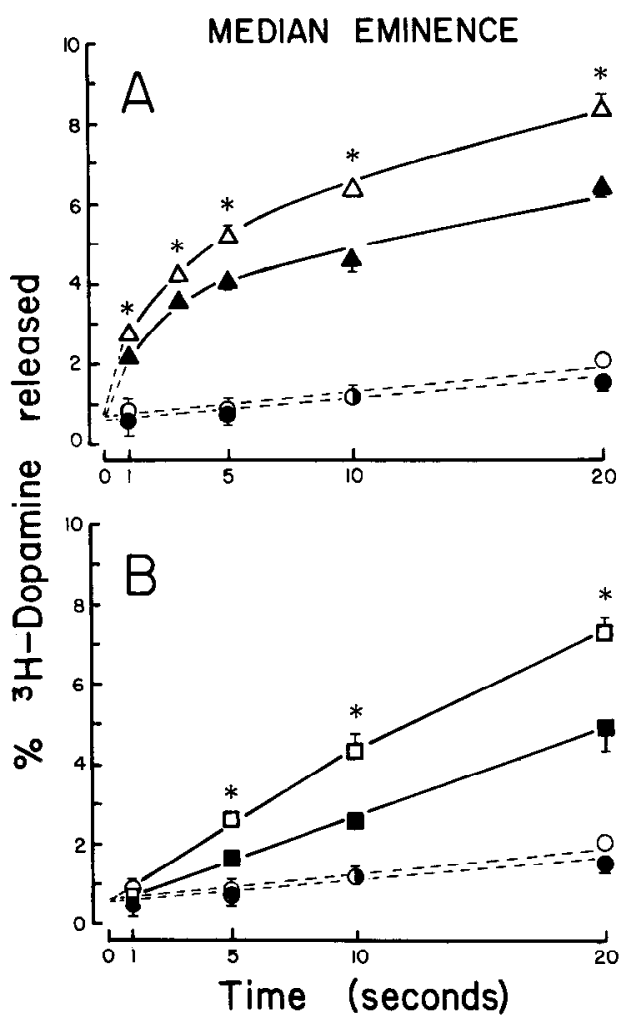

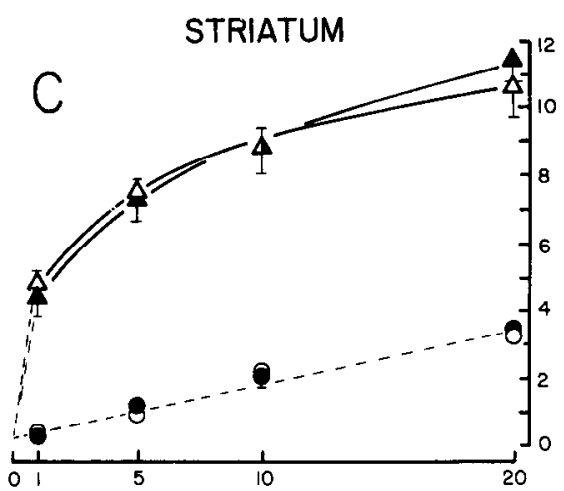

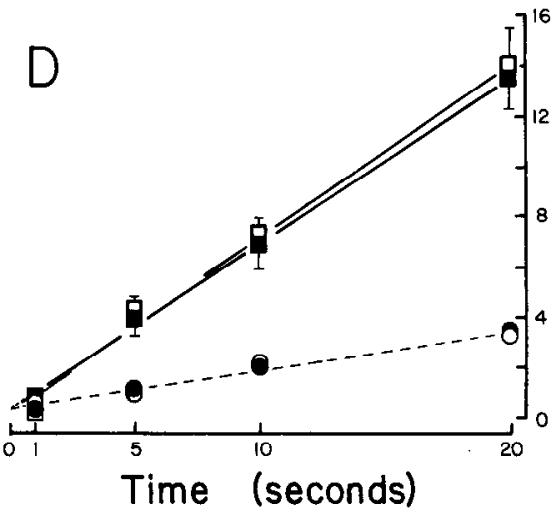

Figure 2. Effect of in vivo oPRL administration on the time course of ${ }^{3} \mathrm{H}-\mathrm{DA}$ efflux from $\mathrm{ME}(A, B)$ and $\mathrm{CS}$ $(C, D)$ synaptosomes. Synaptosomes were prepared from brain tissues of oPRL-treated rats (open symbols) and vehicle-treated controls (closed symbols). Release of preaccumulated ${ }^{3} \mathrm{H}-\mathrm{DA}$ was measured in response to exposure to solutions $\left(30^{\circ} \mathrm{C}\right)$ containing $5 \mathrm{~mm} \mathrm{KCl}$ (all panels; $O$, ), $75 \mathrm{~mm} \mathrm{KCl}(A$ and $C ; \triangle, \Delta)$, or $100 \mu \mathrm{M}$ veratridine in $5 \mathrm{mM}$ $\mathrm{KCl}(B$ and $D ; \square, \square)$. All solutions contained $1 \mathrm{mM} \mathrm{CaCl}_{2}$. Efflux of ${ }^{3} \mathrm{H}-\mathrm{DA}$ was terminated at the times indicated by dilution with ice-cold $5 \mathrm{mM} \mathrm{KCl}$ with $20 \mathrm{mM} \mathrm{NiCl}_{2}$, followed by vacuum filtration. Each symbol represents the mean \pm SEM of values obtained in 3 independent experiments. (Note differences in the scales of the ordinates for ME and CS data.) ${ }^{*}$ Different at $p<0.01$ from corresponding control group. 


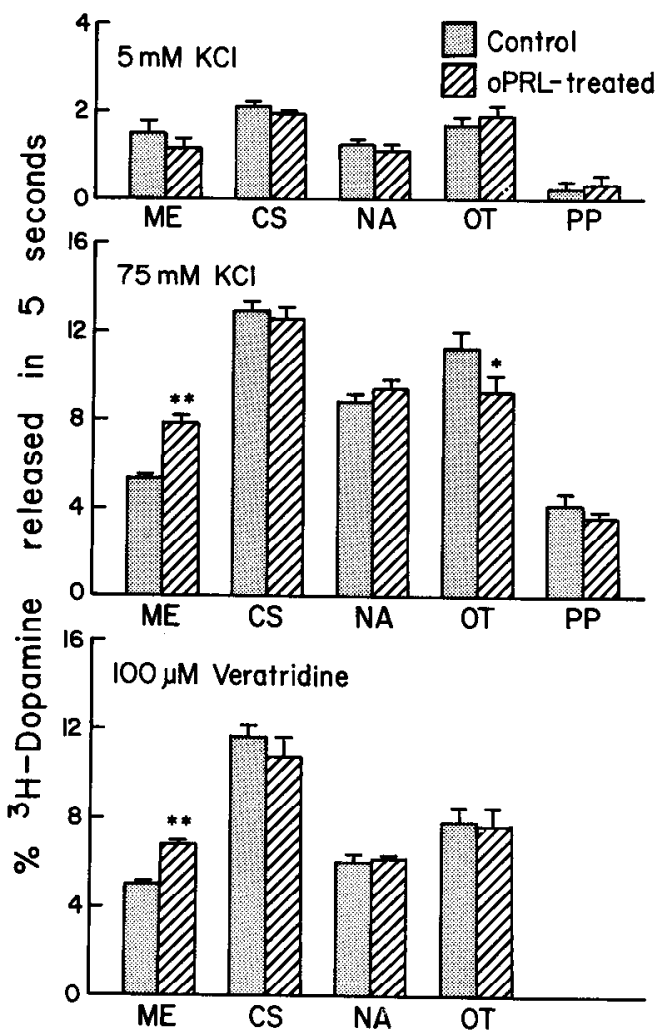

Figure 3. Effect of in vivo oPRL administration on the reiease of ${ }^{3} \mathrm{H}-$ DA from nerve terminals isolated from various central dopaminergic systems. Synaptosomes were prepared from the ME, CS, nucleus accumbens (NA), olfactory tubercle (OT), and posterior pituitary gland (PP) of rats treated with oPRL or vehicle for the preceding $48 \mathrm{hr}$. Release of preaccumulated ${ }^{3} \mathrm{H}-\mathrm{DA}$ was measured during a $5 \mathrm{sec}$ exposure to various stimuli. Data are expressed as means \pm SEM of values obtained in 2 independent experiments. **Different at $p<0.005$ from corresponding control group; *different at $p<0.05$ from corresponding control group.

depolarization was induced by veratridine (Fig. $2 B$ ). Again, the difference between the oPRL and control groups increased as the stimulus was prolonged. In marked contrast, in vivo administration of oPRL had no subsequent effect on fractional release from $\mathrm{CS}$ terminals under any of these conditions (Fig. 2, $C, D$ ).

To further investigate the regional specificity of the oPRL effects on DA release, ${ }^{3} \mathrm{H}-\mathrm{DA}$ efflux was examined in synapto- somes prepared from several dopaminergic terminal projection fields dissected from oPRL- and vehicle-treated rats. These included the nucleus accumbens (NA; mesolimbic), olfactory tubercle (OT; mesolimbic), and posterior pituitary gland (PP; tuberohypophyseal), as well as the CS (nigrostriatal) and $\mathrm{ME}$ (tuberoinfundibular). These data are illustrated in Figure 3. Consistent with previous observations, high $[\mathrm{KCl}]$ - and veratridineinduced ${ }^{3} \mathrm{H}$-DA efflux from $\mathrm{ME}$ terminals was greater in the oPRL-treated group; however, oPRL did not affect basal efflux. We observed no changes in the fractional release of ${ }^{3} \mathrm{H}-\mathrm{DA}$ (basal or depolarization-induced) in response to oPRL-treatment in any of the 4 other preparations with the exccption of the OT. Terminals isolated from this region demonstrated a reduced fractional release in $75 \mathrm{mM} \mathrm{KCl}$ when previously exposed to oPRL. This reduced efflux in oPRL-treated OT preparations was not seen under basal conditions or when depolarization was induced by veratridine.

In this experiment, we again observed that steady-state uptake of ${ }^{3}$ II-DA was decreased in ME and increased in CS following in vivo oPRL administration. No consistent effects of the treatment on steady-state ${ }^{3} \mathrm{H}$-DA uptake into synaptosomes from the NA, OT, or PP were seen (data not shown).

Since PRL has numerous effects on steroidogenesis and steroids can, in turn, alter catecholamine secretion, it was of interest to determine the effect(s) of removing the gonads. We first determined that castrated rats demonstrated a feedback response to elevated circulating PRL. Table 1 presents data showing that basal levels of endogenous rPRL were suppressed in oPRLtreated rats that had been orchidectomized $10 \mathrm{~d}$ earlier, which agrees with reports from other laboratories studying gonadectomized males (Laherty et al., 1983) and females (Nagasawa et al., 1976). Treatment with exogenous oPRL produced a $63 \%$ suppression of basal circulating rPRL in the orchidectomized rats, which is comparable to the $70 \%$ suppression of endogenous rPRL obscrved in intact male rats (Table 1). The ${ }^{3} \mathrm{H}-\mathrm{DA}$ release data from synaptosomes prepared from these animals are illustrated in Figure 4. Release of ${ }^{3} \mathrm{H}-\mathrm{DA}$ from ME, CS, and PP preparations was measured under basal conditions and during depolarization evoked by $75 \mathrm{mM} \mathrm{KCl}$. Only the evoked fractional release from $\mathrm{ME}$ was altered by hyperprolactinemia in the castrated rats. As observed in preparations from intact rats, augmentation of the $\mathrm{KCl}$-induced release by the oPRL treatment was evident at $1 \mathrm{sec}$ of depolarization and increased as the stimulus was maintained.

Table 1. Peripheral serum concentrations of oPRL and endogenous rPRL in intact and orchidectomized male rats with or without oPRL administration

\begin{tabular}{|c|c|c|c|c|}
\hline \multirow[b]{2}{*}{ Animal group ${ }^{\prime}$} & \multirow[b]{2}{*}{ Treatment $^{b}$} & \multirow[b]{2}{*}{$n$} & \multicolumn{2}{|c|}{ Peripheral serum concentration ${ }^{c}$} \\
\hline & & & oPRL (ng/ml) & rPRL (ng/ml) \\
\hline \multirow[t]{2}{*}{ Intact males } & $\mathrm{NaHCO}_{3}$ & 19 & n.d..$^{d}$ & $9.00 \pm 0.99$ \\
\hline & oPRL & 18 & $2286.1 \pm 179.1$ & $2.69 \pm 0.22^{e}$ \\
\hline \multirow{2}{*}{$\begin{array}{l}\text { Orchidectomized } \\
\qquad(10 \mathrm{~d})\end{array}$} & $\mathrm{NaHCO}_{3}$ & 19 & n.d. ${ }^{d}$ & $13.04 \pm 1.67$ \\
\hline & oPRL & 19 & $1050.0 \pm 123.2$ & $4.77 \pm 0.31^{e}$ \\
\hline
\end{tabular}

${ }^{a}$ Although serum samples were analyzed in the same radioimmunoassays, these groups are from 2 separate series of experiments and were injected with different preparations of oPRL. Therefore, no direct comparisons are made between the hormone values of intact and orchidectomized animals.

${ }^{b}$ Injections were administered as described in Materials and Methods.

c Serum was harvested from blood collected between 1 and $2 \mathrm{hr}$ after the final injection of the $48 \mathrm{hr}$ treatment.

${ }^{d}$ n.d., $<1.0 \mathrm{ng} / \mathrm{ml}$.

${ }^{e}$ Different at $p<0.001$ from corresponding control group. 


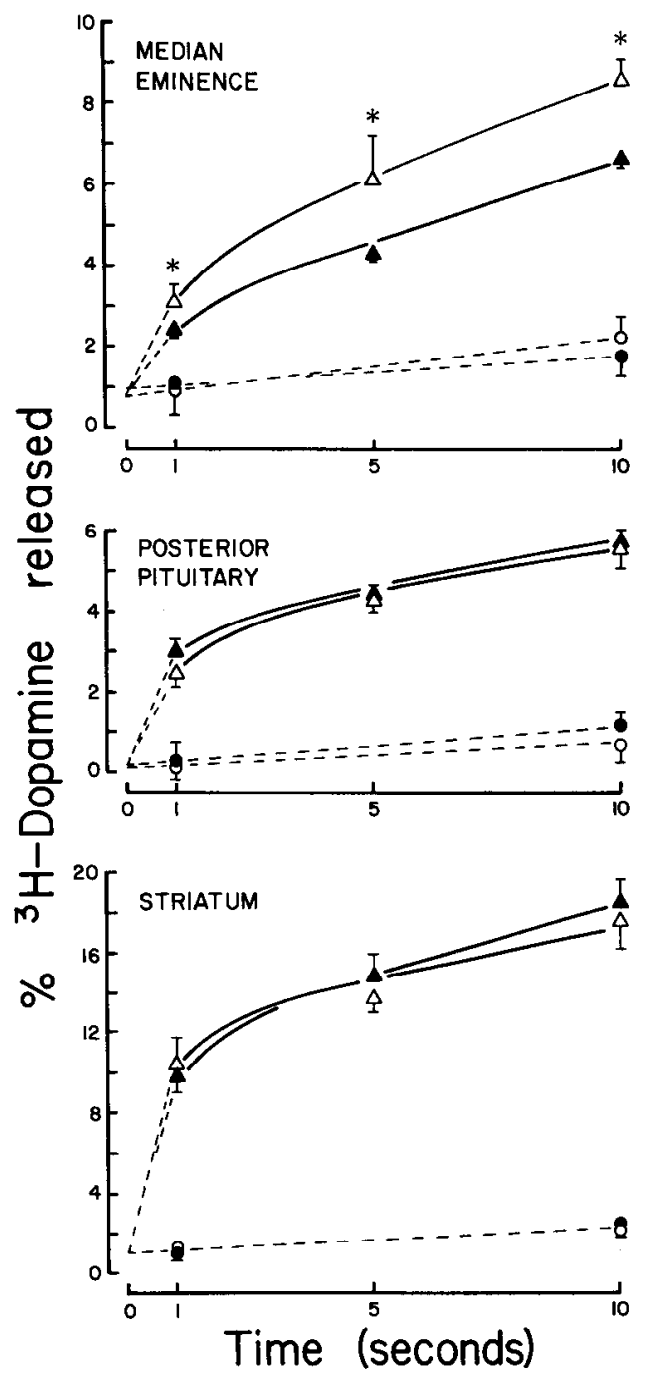

Figure 4. Effect of oPRL administration in orchidectomized rats on the time course of ${ }^{3} \mathrm{H}-\mathrm{DA}$ efflux from subsequently prepared synaptosomes. All animals were bilaterally orchidectomized $10 \mathrm{~d}$ prior to hormone treatment. Nerve terminals were isolated from the ME, PP, and CS of oPRL-treated animals (open symbols) and controls (closed symbols). Release of preaccumulated ${ }^{3} \mathrm{H}$-DA was measured over a $5 \mathrm{sec}$ period under basal conditions $(5 \mathrm{~mm} \mathrm{KCl} ; 0$, $\bullet$ ) or during depolarization induced by $75 \mathrm{mM} \mathrm{KCl}(\Delta, \Delta)$. Data are expressed as means \pm SEM of values obtained in 2 independent experiments. (Note the different scale of the ordinate for the CS data.) *Different at $p<0.005$ from corresponding control group.

Calcium entry has been correlated with ${ }^{3} \mathrm{H}-\mathrm{DA}$ (Drapeau and Blaustein, 1983) and endogenous DA (Leslie et al., 1985) release from CS synaptosomes during the initial seconds of depolarization. We have also shown that ${ }^{3} \mathrm{H}-\mathrm{DA}$ release from ME terminals demonstrates a graded response to increasing concentrations of external $\mathrm{Ca}^{2+}$ (Gregerson and Selmanoff, 1987). Since the oPRL treatment selectively increased the depolarizationinduced ${ }^{3} \mathrm{H}$-DA release from ME, it was of interest to investigate the possible involvement of external calcium in this response. The calcium dose responses of ${ }^{3} \mathrm{H}$-DA efflux in terminals isolated from hyperprolactinemic and control rats arc shown in Figure 5. Increasing external calcium in the $5 \mathrm{mM} \mathrm{KCl}$ solution results in a very small rise in basal release (dashed lines, Fig. 5). In contrast, when the synaptosomes are depolarized, activating voltage-sensitive calcium channels, the efflux of ${ }^{3} \mathrm{H}-\mathrm{DA}$

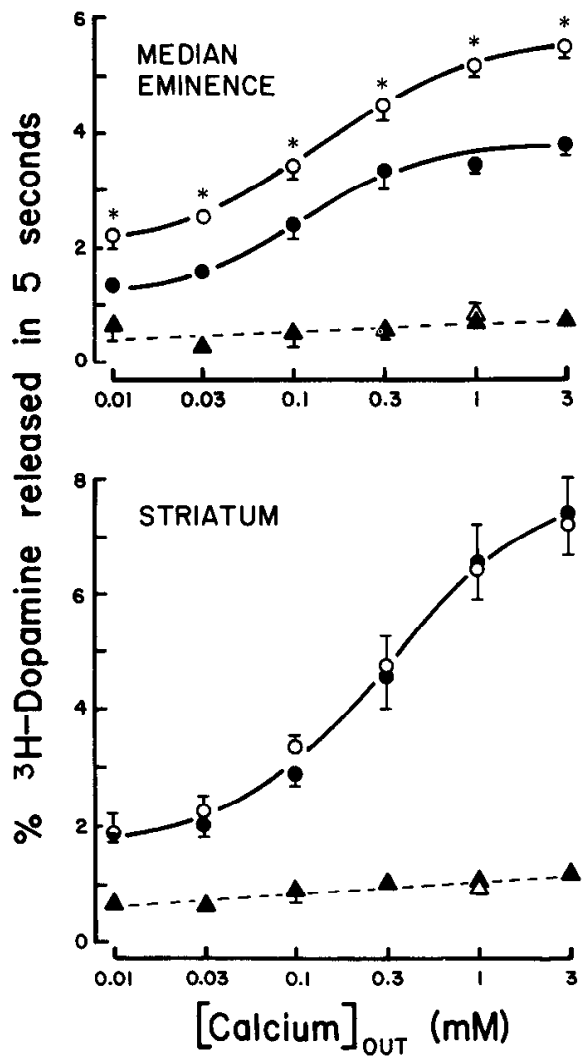

Figure 5. Effect of oPRL treatment on the external calcium dose response of ${ }^{3} \mathrm{H}$-DA efflux. Synaptosomes were prepared from ME and CS of oPRL-trcatcd rats (open symbols) and vchiclc-trcated controls (closed symbols). Basal $(\triangle, \Delta)$ and depolarization-induced $(75 \mathrm{mM} \mathrm{KCl} ; 0, \bullet)$ efflux of ${ }^{3} \mathrm{H}-\mathrm{DA}$ was measured over a period of $5 \mathrm{sec}$. The free $\left[\mathrm{Ca}^{2+}\right]$ contaminating the solutions was approximately $10 \mu \mathrm{M}$ as measured with a Ca ${ }^{2+}$-selective electrode. Sufficient $\mathrm{CaCl}_{2}$ was added to provide total calcium concentrations indicated on the abscissa. Data represent the means \pm SEM of values from 4 independent experiments. *Different at $p<0.001$ from corresponding control group.

displays a graded increase as external calcium is raised from 0.01 to $3 \mathrm{~mm}$ (solid lines, Fig. 5). In synaptosomes from control animals, the apparent half-maximal saturation for calcium $\left(K_{\mathrm{Ca}}\right)$ was $\sim 0.20 \mathrm{~mm}$ for both ME and CS preparations.

PRL treatment resulted in elevated fractional ${ }^{3} \mathrm{H}-\mathrm{DA}$ release from ME synaptosomes during depolarization at all concentrations of external calcium tested (Fig. 5). This produced a doseresponse curve that displayed an upward shift with no change in the apparent half-maximal saturation for calcium, suggesting that the oPRL treatment increased evoked DA release from ME synaptosomes by a mechanism not dependent upon external calcium. To confirm this, release was measured under conditions that would prevent or minimize the actions of external calcium. In one set of experiments, all contaminating free calcium was chelated with EGTA (Fig. 6, bar graphs). In the absence of free external calcium, fractional ${ }^{3} \mathrm{H}-\mathrm{DA}$ release from ME synaptosomes during a $5 \mathrm{sec}$ depolarization was significantly greater in the oPRL-treated group than in vehicle-treated controls (Fig. 6, upper bar graph). In a second study, the release of ${ }^{3} \mathrm{H}$-DA was measured in the presence of $20 \mathrm{mM} \mathrm{NiCl}_{2}$ to block the influx of $\mathrm{Ca}^{2+}$ through voltage-gated channels during the depolarization (Fig. 6, right-hand figures). The external solutions contained total (no EGTA) calcium concentrations to produce (in the absence of $\mathrm{Ni}^{2+}$ ) minimal, half-maximal, and maximal 


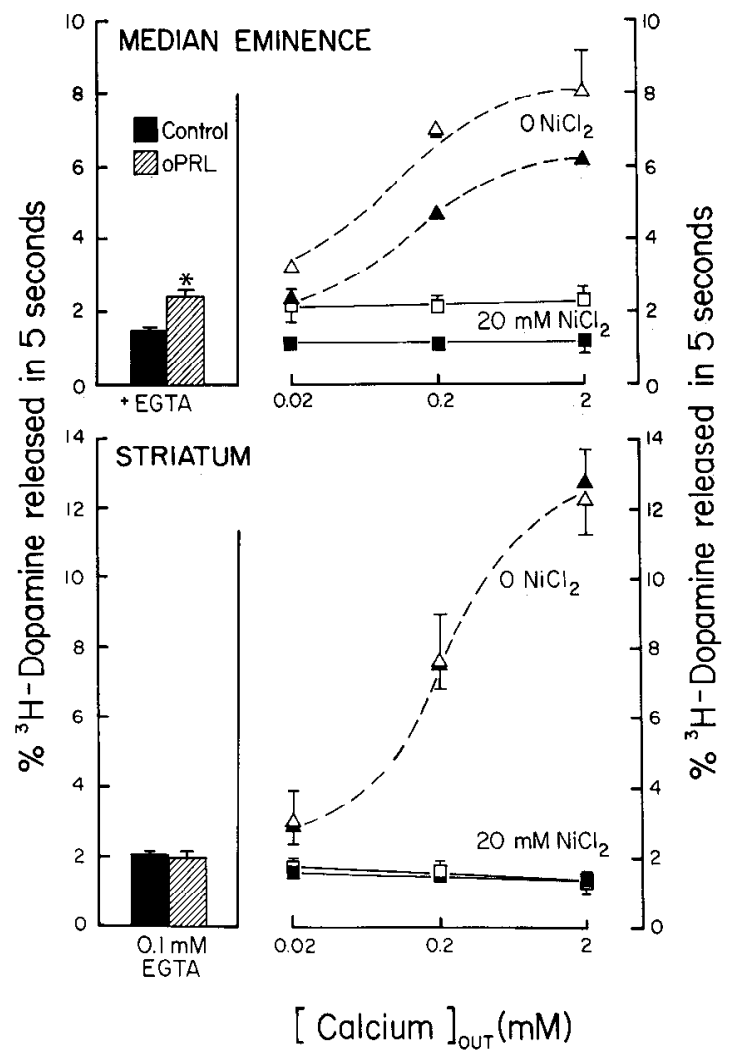

Figure 6. Effect of oPRL treatment on depolarization-induced ${ }^{3} \mathrm{H}-\mathrm{DA}$ efflux independent of external calcium. ${ }^{3} \mathrm{H}-\mathrm{DA}$ released during a $5 \mathrm{sec}$ depolarization $(75 \mathrm{~mm} \mathrm{KCl})$ was measured in synaptosomes prepared from ME and CS of oPRL-treated rats (hatched bars and open symbols) and vehicle-treated controls (shaded bars and closed symbols). The bar graphs represent ${ }^{3} \mathrm{H}$-DA relcased when the contaminating free $\mathrm{Ca}^{2+}(\sim 10$ $\mu \mathrm{M}$ ) in the external solution was bound by $0.1 \mathrm{~mm}$ EGTA (mean \pm SEM of values from 3 independent experiments). The figures on the right illustrate ${ }^{3} \mathrm{H}$-DA released in the absence $(\Delta, \Delta)$ or presence $(\square, \square)$ of 20 $\mathrm{mM} \mathrm{NiCl}_{2}$ in external solutions containing calcium concentrations (total; no EGTA) indicated on the abscissa. These data are the means \pm SEM of values obtained from 2 independent experiments. ${ }^{*}$ Different at $p<$ 0.001 from vehicle-treated control.

release responses to $75 \mathrm{mM} \mathrm{KCl}$ (as determined from data in Fig. 5). That the $20 \mathrm{mM} \mathrm{NiCl}_{2}$ completely blocked the influx of calcium ions during depolarization with $75 \mathrm{~mm} \mathrm{KCl}$ is supported by the absence of a change in ${ }^{3} \mathrm{H}$-DA release as external calcium is raised from 0.02 to $2.0 \mathrm{~mm}$. This block was effective in both $\mathrm{ME}$ and CS preparations (Fig. 6, square symbols versus triangles). However, the $\mathrm{Ni}^{2+}$ did not block the oPRL-induced elevation in ${ }^{3} \mathrm{H}$-DA release from $\mathrm{ME}$ synaptosomes, confirming that this response is independent of depolarization-induced $\mathrm{Ca}^{2+}$ influx.

\section{Discussion}

In the present studies, we have demonstrated that short-term hyperprolactinemia, which decreases endogenous PRL secretion in vivo, produces significant augmentation of ${ }^{3} \mathrm{H}-\mathrm{DA}$ release evoked from the isolated tuberoinfundibular nerve terminals. This oPRL-induced elevation in ${ }^{3} \mathrm{H}-\mathrm{DA}$ release is (1) specific to stimulated release, having no effect on basal DA efllux, and (2) is not dependent upon external calcium. This effect of oPRL treatment appears to be specific to the TIDA neurons since it had no similar effect in preparations of mesolimbic, nigrostriatal, or tuberohypophyseal dopaminergic nerve terminals. In the ME terminals from hyperprolactinemic animals, the increased ${ }^{3} \mathrm{H}$-DA release is evident during the fast component (initial release in $1 \mathrm{sec}$ ) of $\mathrm{KCl}$-evoked release and also displays a slower, time-dependent component with prolonged depolarization. In addition to an enhanced release of ${ }^{3} \mathrm{H}-\mathrm{DA}, \mathrm{ME}$ synaptosomes from oPRL-treated animals demonstrated a significantly decreased steady-state uptake of ${ }^{3} \mathrm{H}-\mathrm{DA}$ compared with control preparations. In situ decreased reuptake of DA into $\mathrm{ME}$ terminals and augmented DA release during a given stimulus would both act to increase the amount of DA available to lactotrophs in the anterior pituitary gland via the hypophyseal portal vasculaturc, lcading to subscquent suppression of PRL secretion (Table 1). Indeed, PRL treatment has been shown to elevate portal blood DA in rats (Gudelsky and Porter, 1980).

The regional specificity of the synaptosome responses lends support to the possibility that they are part of a physiological response in a short-loop feedback system in PRL regulation. Among the dopaminergic regions examined, only the tuberoinfundibular terminals demonstrated increased evoked release and suppressed steady-state uptake following oPRL treatment (Fig. 3). No PRL-induced alterations in either ${ }^{3} \mathrm{H}-\mathrm{DA}$ uptake or release were observed in synaptosomes prepared from the posterior pituitary gland, although it has been suggested that these neurons also play a role in PRL regulation (Peters et al., 1981). Consistent with our findings, Moore and Demarest (1982) reported no effect of PRL treatment on either DA synthesis or turnover rates in the posterior pituitary. This study and ours utilized the whole neurointermediate unit, which may account for the lack of response to hyperprolactinemia. In examining DA receptor-mediated regulatory mechanisms, Lookingland and coworkers (1985) observed markedly different responses in the isolated neural lobe and on the isolated intermediate lobe of the PP. Such a differential response in the 2 lobes to other stimuli (i.e., PRL) may account for an obscured response when examining the combined neurointermediate hypophyseal unit. Alternatively, the present data may be an accurate manifestation of differential actions of hyperprolactinemia on the tuberohypophyseal and tuberoinfundibular neurons.

The PRL-induced changes in the uptake and release of ${ }^{3} \mathrm{H}-$ DA in ME synaptosomes does not require the presence of the testes (Fig. 4). This is consistent with reports that exogenous PRL-induced suppression of endogenous PRL release occurs in orchidectomized rats (Laherty et al., 1983; present report, Table 1). This does not obviate an intermediary role for the adrenal gland (where PRL has been shown to alter androgen production: Higuchi et al., 1984), for other central neurons, or for the cell body of the DA neuron since our examination of the isolated terminals followed in vivo treatment with oPRL. Specific, highaffinity binding sites for PRL have been identified in rat ME and arcuate nucleus (Walsh et al., 1978), and, in rabbit hypothalamus, the number of these binding sites has been shown to vary after administration of PRL regulators or PRL itself (Di Carlo and Muccioli, 1981). These findings are consistent with a direct action of PRL in the brain, although they do not distinguish between the perikarya and the terminals of the TIDA neurons, nor do they rule out possible PRL effects on intermediary neurons. Preliminary studies in which ME synaptosomes prepared from untreated rats were exposed to oPRL or rPRL in vitro showed no effect of PRL on the release of ${ }^{3} \mathrm{H}-\mathrm{DA}$ (Gregerson and Selmanoff, unpublished observations). In these studies, the synaptosomes were preincubated with PRL (1-10 $\mu \mathrm{g} / \mathrm{ml}$ ) for up to $30 \mathrm{~min}$ prior to testing ${ }^{3} \mathrm{H}-\mathrm{DA}$ release. It may 
be that PRL does not exert its effects directly at the presynaptic membrane but requires either the intact DA neuron or its in situ connections with other neurons. This seems possible in light of studies by Foreman and Porter (1981) and Perkins and Westfall (1978) in which in vitro application of PRL to hypothalamic slices, which contained intact tuberoinfundibular neurons, resulted in elevated DA release during stimulation.

The observed decrease in the steady-state accumulation of ${ }^{3} \mathrm{H}$-DA in ME synaptosomes from oPRL-treated rats could be an action of PRL on the DA uptake carrier, either direct or indirect. Lee and coworkers (1983) presented evidence that the intraterminal concentration of norepinephrine (NE) regulates the density of NE uptake recognition sites on the synaptosomal membrane. The data demonstrated that depletion of NE leads to a reduction in the number of uptake sites. In our studies, if the rate of DA synthesis in the TIDA neurons does not match the increased rate of DA release following PRL treatment, the resulting decrease in intraterminal DA may, in turn, lead to fewer DA uptake sites. Consistent with this are our previous observations (Selmanoff, 1985; Mechanick et al., 1987) that ME DA content is significantly reduced following $26-48 \mathrm{hr}$ of oPRL administration.

Since net accumulation is the balance between uptake and release, it is conceivable that the change in one process is merely a reflection of a change in the other. Augmented release of ${ }^{3} \mathrm{H}$ DA induced by PRL could produce an apparent decrease in uptake. Conversely, a PRL-induced reduction in steady-state uptake may account for an apparent increase in fractional release. However, the failure of PRL to alter the basal release of ${ }^{3} \mathrm{H}$-DA from the ME terminals argues against these simple cases. The mechanisms underlying the PRL-induced changes in DA uptake and release in ME synaptosomes may be related, but one change does not wholly account for the other.

An increased steady-state incorporation of ${ }^{3} \mathrm{H}-\mathrm{DA}$ into CS synaptosomes prepared from oPRL-treated rats was a consistent observation in all of the studies presented here. We have previously reported this effect of PRL on ${ }^{3} \mathrm{H}-\mathrm{DA}$ uptake in the striatum (Gregerson and Selmanoff, 1984). In analyzing the kinetics of this system, oPRL treatment in vivo was found to enhance maximal rate of ${ }^{3} \mathrm{H}-\mathrm{DA}$ uptake into CS synaptosomes without altering the affinity of the carrier for the amine. Supportive findings have been reported by Chen and Ramirez (1982), who, using a push-pull perfusion technique, observed a PRLinduced increase in rat striatal DOPAC, but not DA, in vivo. Our evidence is that hyperprolactinemia can, either directly or indirectly, produce alterations in DA transport in nigrostriatal terminals. There is ample precedent for modulatory effects of PRL on behavior in mammals (Nicoll, 1974). The CS, a basal ganglia structure involved in the processing of motor, sensory, and motivational sensations (Marsden, 1980), is a possible site of action for these effects. Specific, high-affinity binding sites for PRL have been identified in the substantia nigra and the striatum of the rabbit (Di Carlo et al., 1985). Although the bloodbrain barrier may limit the accessibility of these regions to vascular PRL, it is possible that PRL could be delivered to these brain areas by a CSF route. PRL concentrations in the CSF parallel the serum concentrations in rats and humans (Login and MacLeod, 1977) and the high density of PRL binding sites found on the choroid plexus of rats (Walsh et al., 1978) may play a role in the uptake of PRL from blood into CSF.

Yamada (1975), recording the single-unit activity of hypothalamic neurons, demonstrated increased firing rates in re- sponse to iontophoretically applied PRL. Although the manipulations used in the present report may not induce depolarization by the same mechanisms as the physiological stimulators of DA release, they serve as useful probes for elucidating the basic responses of these neurons.

It can be concluded from the present data, which were obtained in experiments using $\mathrm{KCl}$ and veratridine to elicit depolarization of isolated nerve terminals, that (1) PRL treatment will augment DA release from ME synaptosomes during depolarization, and (2) this augmentation involves a release of DA that is independent of external calcium. Clearly, further studies are required to better define the specific sites and pathways involved in PRL actions in the brain. For example, the possible involvement of intrasynaptosomal stores of calcium in the PRLsensitive DA release from ME is yet to be determined. Nonetheless, it is impressive that alterations in TIDA neurons resulting from exposure to elevated circulating oPRL levels in vivo are preserved in vitro in terminals isolated by a procedure involving homogenizations of treated and control tissues in identical solutions. Whether the observed changes are due to direct actions of PRL on the TIDA neurons or not, it is clear that the responses are translated into long-term alterations of function at the nerve terminal.

\section{References}

Annunziato, L., and K. E. Moore (1978) Prolactin in CSF selectively increases dopamine turnover in the median eminence. Life Sci. 22: 2037-2041.

Blaustein, M. P., and J. M. Goldring (1975) Effects of potassium, veratridine and scorpion venom on calcium accumulation and transmitter release by nerve terminals in vitro. J. Physiol. (Lond.) 247: 589-615.

Bradford, M. M. (1976) A rapid and sensitive method for the quantitation of microgram quantities of protein utilizing the principles of protein-dye binding. Anal. Biochem. 72: 248-254.

Bruinvels, J. (1975) Role of sodium in neuronal uptake of monoamines and aminoacid precursors. Nature 257: 606-607.

Chen, Y.-F., and V. D. Ramirez (1982) Prolactin stimulates dopamine release from male but not from female rat striatal tissue superfused in vitro. Endocrinology 111: 1740-1742.

Clemens. J. A., and J. Meites (1968) Inhibition by hypothalamic prolactin implants of prolactin secretion, mammary growth and luteal function. Endocrinology 82: 878-881.

Cramer, O. M., C. R. Parker, and J. C. Porter (1979) Secretion of dopamine into hypophysial portal blood by rats bearing prolactinsecreting tumors or ectopic pituitary glands. Endocrinology 105:636640 .

Di Carlo, R., and G. Muccioli (1981) Presence of specific prolactin binding sites in the rabbit hypothalamus. Life Sci. 28: 2299-2317.

Di Carlo, R., G. Muccioli, D. Lando, and G. Bellussi (1985) Further evidence for the presence of specific binding sites for prolactin in the rabbit brain. Preferential distribution in the hypothalamus and substantia nigra. Life Sci. 36: 375-382.

Drapeau, P., and M. P. Blaustein (1983) Initial release of [ $\left.{ }^{3} \mathrm{H}\right]$ dopamine from rat striatal synaptosomes: Correlation with calcium entry. $\mathrm{J}$. Neurosci. 3: 703-713.

Foreman, M. M., and J. C. Porter (1981) Prolactin augmentation of dopamine and norepinephrine release from superfused medial basal hypothalamic fragments. Endocrinology 108: 800-804.

Gregerson, K. A., and M. Selmanoff (1984) Effects of hyperprolactinemia on dopamine uptake into striatal synaptosomes in vitro. In Prolactin: Basic and Clinical Correlates, Vol. 1, R. M. MacLeod, M. O. Thorner, and U. Scapagnini, eds., pp. 625-631, Liviana Press, Padova.

Gregerson, K. A., and M. Selmanoff (1987) Rapid release of $\left[{ }^{3} \mathrm{H}\right]$ dopamine from median eminence and striatal synaptosomes. J. Neurochem. 48: 1222-1230.

Gudelsky, G. A, and J. C. Porter (1980) Release of dopamine from tuberoinfundibular neurons into pituitary stalk blood after prolactin or haloperidol administration. Endocrinology 106: 526-529. 
Gudelsky, G. A., J. Simpkins, G. P. Mueller, J. Meites, and K. E. Moore (1976) Selective actions of prolactin on catecholamine turnover in the hypothalamus and on serum LH and FSH. Neuroendocrinology 22: 206-215

Hajos, F. (1975) An improved method for the preparation of synaptosomal fractions in high purity. Brain Res. 93: 485-489.

Higuchi, K., H. Nawata, T. Maki, M. Higashizima, K.-I. Kato, and H. Ibayashi (1984) Prolactin has a direct effect on adrenal androgen secretion. J. Clin. Endocrinol. Metab. 59: 714-718.

Höhn, K. G., and W. O. Wuttke (1978) Changes in catecholamine turnover in the anterior part of the mediobasal hypothalamus and the medial preoptic area in response to hyperprolactinemia in ovariectomized rats. Brain Res. 156: 241-252.

Hökfelt, T., and K. Fuxe (1972) Effects of prolactin and ergot alkaloids on the tuberoinfundibular dopamine (DA) neurons. Neuroendocrinology 9: 100-122.

Huynh, H., and L. S. Feldt (1970) Conditions under which mean square ratios in repeated measurement designs have exact F-distributions. J. Am. Stat. Assoc. 65: 1582-1589.

Koe, B. K. (1976) Molecular geometry of inhibitors of the uptake of catecholamines and serotonin in synaptosomal preparations of rat brain. J. Pharmacol. Exp. Ther. 199: 649-661.

Krueger, B. K., R. W. Katzlaff, G. R. Strichartz, and M. P. Blaustein (1979) Saxitoxin binding to synaptosome membranes and solubilized binding sites from rat brain. J. Membr. Biol. 50: 287-310.

Laherty, R. F., J. M. Budd, and H. H. Srebnik (1983) Inhibition of prolactin secretion by rat placental extract. Proc. Soc. Exp. Biol. Med. 172: 29-33.

Lee, C.-H., J. A. Javitch, and S. H. Snyder (1983) Recognition sites for norepinephrine uptake: Regulation by neurotransmitter. Science 220: 626-629.

Leong, D. A., L. S. Frawley, and J. D. Neill (1983) Neuroendocrine control of prolactin secretion. Annu. Rev. Physiol. 45: 109-127.

Leslie, S. W., J. J. Woodward, and R. E. Wilcox (1985) Correlation of rates of calcium entry and endogenous dopamine release in mouse striatal synaptosomes. Brain Res. 325: 99-105.

Login, I. S., and R. M. MacLeod (1977) Prolactin in human and rat serum and cerebrospinal fluid. Brain Res. 132: 477-483.

Lookingland, K. J., J. M. Farah, K. L. Lovell, and K. E. Moore (1985) Differential regulation of tuberohypophysial dopaminergic neurons terminating in the intermediate lobe and in the neural lobe of the rat pituitary gland. Neuroendocrinology 40: 145-151.

Marsden, C. D. (1980) The enigma of the basal ganglion and movement. Trends Neurosci. 3: 284-287.

Mechanick, J. I., I. R. Cohen-Becker, K. A. Gregerson, and M. Selmanoff (1987) Distribution of 3,4-dihydroxyphenylacetic acid (DOPAC) and 3,4-dihydroxyphenylglycol (DOPEG) in microdissected brain structures and the pituitary gland: Metabolite changes in the median eminence in response to hyperprolactinemia and suckling. J. Neural. Transm. 68: 197-215.

Moore, K. E., and K. T. Demarest (1982) Tuberoinfundibular and tuberohypophysial dopaminergic neurons. In Frontiers in Neuroen- docrinology, Vol. 7, W. F. Ganong and L. Martini, eds., pp. 161-190, Raven, New York.

Nagasawa, H., R. Yanai, and K. Yamanouchi (1976) Inhibition of pituitary prolactin secretion by human placental lactogen in rats. J. Endocrinology 71: 115-120.

Nicoll, C. S. (1974) Physiological actions of prolactin. In Harudbook of Physiology, Section 7: Endocrinology, Vol. 4, Part 2, R. O. Greep and E. B. Astwood, eds., pp. 253-267, American Physiological Society, Washington, D.C.

Niswender, G. D., C. L. Chen, A. R. Midgley, J. Meites, and S. Ellis (1969) Radioimmunoassay for rat prolactin. Proc. Soc. Exp. Biol. Med. 130: 793-797.

Olson, L., K. Fuxe, and T. Hökfelt (1972) The effect of pituitary transplants on the tubero-infundibular dopamine neurons in various endocrine states. Acta Endocrinol. (Copenh.) 71: 233-244.

Perkins, N. A., and T. C. Westfall (1978) Effect of prolactin on dopamine release from rat striatum and medial basal hypothalamus. Neuroscience 3: 59-63.

Perkins, N. A., T. C. Westfall, C. V. Paul, R. M. MacLeod, and A. D. Rogol (1979) Efrect of prolactin on dopamine synthesis in medial basal hypothalamus: Evidence for a short loop feedback. Brain Res. 160: $431-444$

Peters, L. L., M. T. Hoefer, and N. Ben-Jonathan (1981) The posterior pituitary: Regulation of anterior pituitary prolactin secretion. Science 213: 659-661.

Raiteri, M., and G. Levi (1978) Release mechanisms for catecholamines and serotonin in synaptosomes. Rev. Neurosci. 3: 77-130.

Rouanet, H., and D. Lepine (1970) Comparison between treatments in a repeated-measurement design: ANOVA and multivariate methods. Br. J. Math. Stat. Psychol. 23: 147-163.

SAS Institute, Inc. (1985) SAS User's Guide: Statistics, Version 5, SAS Institute, Inc., Cary, NC.

Selmanoff, M. (1981) The lateral and medial median eminence: Distribution of dopamine, norepinephrine, and luteinizing hormone-releasing hormone and the effect of prolactin on catecholamine turnover. Endocrinology 108: 1716-1722.

Selmanoff, M. (1985) Rapid effects of hyperprolactinemia on basal prolactin secretion and dopamine turnover in the medial and lateral median eminence. Endocrinology 116: 1943-1952.

Selmanoff, M., and K. A. Gregerson (1984) Autofeedback effects of prolactin on basal, suckling-induced, and proestrus secretion of prolactin. Proc. Soc. Exp. Biol. Med. 175: 398-405.

Walsh, R. J., B. I. Posner, B. M. Kopriwa, and J. R. Brawer (1978) Prolactin binding sites in the rat brain. Science 201: 1041-1043.

Weiner, R. I., M. J. Cronin, C. Y. Cheung, L. Annunziato, N. Faure, and P. C. Goldsmith (1979) Dopamine: A prolactin inhibitory hormone. In Neuroendocrine Correlates in Neurology and Psychiatry, E. E. Müller and A. Angoli, eds., pp. 41-55, Elsevier, Amsterdam.

Winer, B. J. (1971) Statistical Principles in Experimental Design, 2nd ed., pp. 85-94, 514-517, 539-576, 594-599, McGraw-Hill, New York.

Yamada, Y. (1975) Effects of iontophoretically-applied prolactin on unit activity of the rat brain. Neuroendocrinology $18: 263-271$. 